\title{
Research article \\ Role of MMP 9 in the diagnosis and management of pulmonary tuberculosis and its association with nutritional status
}

\author{
Aishwarya G. Warrier ${ }^{1}$, Reshma Kumarchandra ${ }^{1}$, Sudha Kuthethur ${ }^{1}$, Jayashree Bhat B. ${ }^{2}$, Durgarao Yalla ${ }^{1}$ \\ ${ }^{1}$ Department of Biochemistry, Kasturba Medical College, Mangalore, Manipal Academy of \\ Higher Education, Manipal, India \\ ${ }^{2}$ Medical Officer, RNTCP/DOTS Centre, Government Wenlock \\ Hospital, Mangaluru, Karnataka, India
}

(Received: September $2020 \quad$ Revised: February $2021 \quad$ Accepted: March 2021)

Corresponding author: Reshma Kumarchandra. Email: reshma.kc@manipal.edu

\begin{abstract}
Introduction and Aim: Etiopathogenesis of Pulmonary tuberculosis (PTB), is well established. Yet, the mechanisms by which a treatment regimen brings about remodelling of the pulmonary tissue during recovery phase is not well understood. The involvement of matrix metalloproteinase in this regard is debated, due to its dual role, either in disseminating the disease due to lung cavitation or reducing the inflammation due to recruitment of macrophages to the lung granulomas. PTB is a disease also driven by undernourishment. This study focuses on the association of nutritional status of PTB patients in restoring healthy lung tissue, monitored by blood levels of albumin, iron and MMP9, during the course of intensive treatment.

Materials and Methods: Serum levels of MMP9, iron, Total protein and albumin were estimated in 30 PTB patients who visited the Directly Observed Treatment Short course (DOTS) Centre at Government Wenlock Hospital, Mangalore, Karnataka, India. Twenty controls were enrolled for comparative statistics. Samples were collected at baseline and after two months of DOTS treatment in case of patients. Pre-treatment and post treatment values were compared by paired t test. Student's ' $t$ ' test was used for comparing parameters in controls and patients. Correlation between parameters was done by Pearson's correlation test.
\end{abstract}

Results: A significant increase was observed in serum iron $(P=0.002)$ and total protein $(P=0.01)$ levels post treatment but there was no significance in the levels of MMP9. Further, serum MMP9 correlated negatively with body weight, BMI and serum total protein levels, post treatment, which was statistically significant. No other correlations were significant.

Conclusion: We conclude that MMP9 neither seems to be a diagnostic marker nor a therapeutic target in the treatment of tuberculosis. Although serum iron appears to be a predictor of improved nutritional status post treatment, it probably may have a role in tissue remodelling independent of MMP-9.

Keywords: MMP9; pulmonary tuberculosis; albumin; iron; DOTS therapy.

\section{INTRODUCTION}

$\mathrm{P}$ ulmonary Tuberculosis (PTB) remains a global health pandemic, caused by a bacterium Mycobacterium tuberculosis (MTB). It is estimated that $1 / 3^{\text {rd }}$ of earth's population is infected by MTB $(1,2)$. Each year India has 2.2 million new cases of PTB and more than 3 lakh death from it, making it India's biggest health crisis (3).

Infection of MTB is usually targeted towards the macrophages leading to up regulation of Matrix metalloproteinase (MMP) secretion in PTB. Once the MTB reaches the lung interstitium, breakdown of extra cellular matrix occurs leading to the dissemination of pathogen through the airways. Extensive lung matrix destruction leads to cavitation which is a result of MMP activity further aiding in the progression of the disease (1).

A wide variety of MMPs have been identified to date of which MMP-1 and MMP-7 are expressed by epithelioid macrophages and Langerhans giant cells in lung granulomas (4) and MMP-1 and MMP-9 are expressed by pulmonary epithelial cells $(5,6)$. In lymph node tuberculosis, both epithelioid macrophages and multinucleate giant cells express MMP-9 (7).

Tuberculosis patients have significantly lower nutritional status which may lead to secondary immunodeficiency in turn making the host more vulnerable to infection. In adults with pulmonary tuberculosis, serum albumin and serum iron level are found to be strong predictors of survival (8). PTB is often associated with normocytic normochromic anaemia or hypochromic microcytic anaemia (9). Infection with MTB is also reported to produce hypoalbuminemia in patients (10), albumin being a negative acute phase protein.

Treatment with anti-tuberculosis drugs should generally improve the immune status and associated anaemia in addition to killing the pathogen. 
Aims and objectives: To estimate serum MMP-9 levels in patients with pulmonary tuberculosis and correlate it with nutritional status using serum albumin and iron levels as indices before and after two months of Directly Observed Treatment Short course (DOTS) and determine if the treatment has any effect on lung damage and associated nutritional deficiencies.

\section{Subjects and Methods}

The study population consisted of 30 cases of newly diagnosed PTB as defined by Revised National Tuberculosis Control Program (RNTCP) regimen on the basis of sputum smear positive for acid fast bacilli, MTB on Ziehl-Neelsen staining method (11). These patients were followed up after two months of intensive phase treatment. The samples of PTB patients were collected from the DOTS Centre in Government Wenlock Hospital, Mangalore, Karnataka, India. The study was approved by Institutional Ethical Committee, Clearance No. IEC KMC MLR 12-17/276

Sample size for the study was determined as follows

Sample size: Based on statistics, the number of samples collected would be as follows:

$$
\mathrm{n}=\frac{Z_{\alpha^{2} \sigma^{2}}}{d^{2}}
$$

$\mathrm{Z} \alpha=1.96$ at $95 \%$ confidence interval

$\sigma=$ standard deviation

$\mathrm{d}=$ mean value $(20 \%$ relative precision)

With $95 \%$ confidence level and $80 \%$ power with respect to mean $=3.29$ and $\mathrm{S} . \mathrm{D}=1.16$ (albumin) the sample size is derived to be 25 .

25 patients will constitute pretreatment and these 25 are followed up, after DOTS (Directly Observed Therapy Short term) treatment.

Serum samples of 20 controls with no tuberculosis or any other infectious diseases and systemic illness were collected from Kasturba Medical College Hospital, Ambedkar Circle, Mangalore, Karnataka, India.

\section{Inclusion criteria}

The patients included were newly diagnosed cases of PTB of both sexes in the age group of 18 to 65 years from in and around Mangalore, Dakshina Kannada district, Karnataka State, India. The patients were advised to strictly refrain from the habits of smoking and alcohol consumption during the treatment.

\section{Exclusion criteria}

Patients with infectious diseases other than tuberculosis, systemic illness or any comorbid conditions were excluded from the study.

The study protocol was approved by the Ethics Committee of Kasturba Medical College, Mangalore, Karnataka, India. The written informed consent and proforma containing details of patients were collected from the patients

\section{DOTS Treatment}

DOTS plus facility was implemented by RNTCP, a Government of India initiative working under WHO recommendations. The regimen consists of two months of intensive therapy with HRZE followed by continuation with RH for four months $\{\operatorname{Isoniazid}(\mathrm{H})$, Rifampicin(R), Pyrazinamide(Z), Ethambutol(E) to the category I patients $\}$.

\section{Biochemical analysis}

Random blood samples were collected from the patients in a sterile plain vacutainer. Serum was separated and stored at $-20^{\circ} \mathrm{C}$. Sample was collected prior to and after two months of DOTS treatment.

Serum MMP-9 was estimated using human MMP-9 ELISA kit. Assay was based on Sandwich ELISA technique (12). Serum iron was determined by Iron Chromazurol method using semi-autoanalyzer, spectrophotometrically (13). Determination of serum albumin was done by Bromocresol Green (BCG) method and that of total protein by Biuret method using semi-autoanalyzer $(14,15)$.

\section{Statistical analysis}

The data was analysed using SPSS version 17. Comparison between the parameters before and after treatment were done using Students Paired t-test and Students $t$ - test was done to compare parameters with pre-treated patients and controls. Correlation between the parameters was analysed using Karl Pearson's Correlation Coefficient. $P<0.05$ was considered as statistically significant. Specificity and Sensitivity of MMP-9 in the disease was calculated from ROC curve.

\section{RESULTS}

Serum MMP-9: A total of 30 patients were included in the study and from these only 23 were followed up. The mean age of the study group $41.43 \pm 16.65$ years. There was no significant difference in MMP9 levels between the PTB patients' pre-treatment and post treatment compared to controls as shown in table 1.

Table 1: Serum MMP-9 levels (pg/ml) in patients and controls

\begin{tabular}{|c|c|c|}
\hline Controls (n=20) & $\mathbf{4 9 0 5 . 2 3 ~} \pm \mathbf{3 9 3 . 4}$ & $\boldsymbol{P}$ value \\
\hline Patients (Baseline; $\mathrm{n}=30)$ & $4746.997 \pm 933.53$ & 0.464 \\
\hline $\begin{array}{c}\text { Patients (Post treatment; } \\
\mathrm{n}=23)\end{array}$ & $4448.84 \pm 1044.75$ & 0.126 \\
\hline
\end{tabular}

Table 2: Area under the curve for MMP9 in patients and controls

\begin{tabular}{|c|c|c|c|}
\hline Test variables & Area & Sensitivity & Specificity \\
\hline $\begin{array}{c}\text { MMP-9 control } \\
\text { vs Prior treatment } \\
\text { patient group }\end{array}$ & 0.500 & $65.2 \%$ & $75 \%$ \\
\hline $\begin{array}{c}\text { MMP-9 control } \\
\text { vs post DOTS } \\
\text { treatment patient } \\
\text { group }\end{array}$ & 0.310 & $53 \%$ & $75 \%$ \\
\hline
\end{tabular}




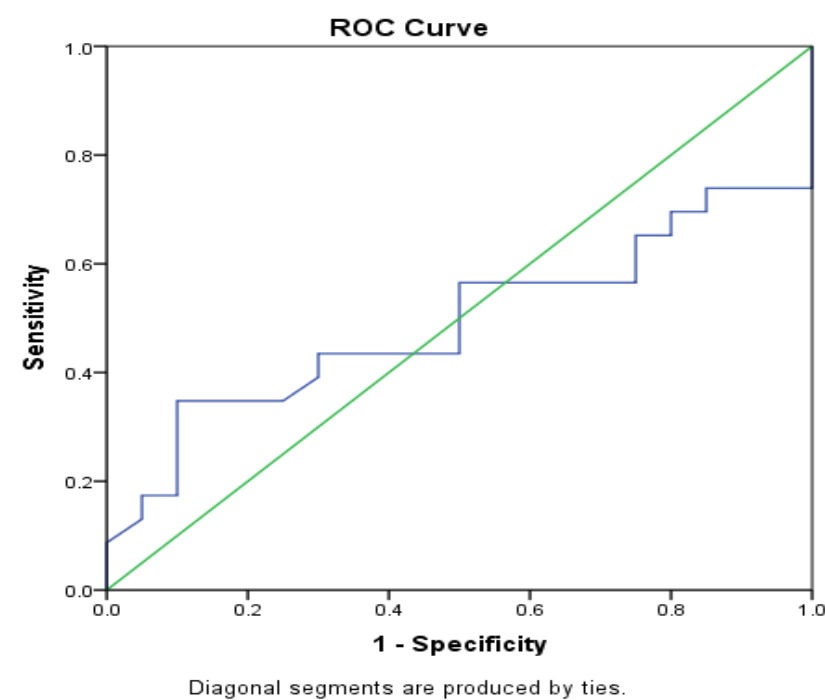

Fig 1A: ROC Curve depicting MMP-9 levels of controls and patients prior to treatment

The values of AUC in the ROC curve for MMP9 in controls and patients at baseline and post treatment were $\leq 0.5$ with no significant outcome (table 2 , Fig. $1 \mathrm{~A}$ $\& 1 \mathrm{~B})$.

\section{BMI and nutritional status}

Table 3: Comparison of demographical and biochemical parameters between baseline and post DOTS treatment in patients

\begin{tabular}{|c|c|c|c|}
\hline Parameters & $\begin{array}{c}\text { Pre-treatment } \\
\text { Mean } \pm \text { S.D.(n=30) }\end{array}$ & $\begin{array}{c}\text { Post treatment } \\
\text { Mean } \pm \text { S.D.(n=23) }\end{array}$ & P value \\
\hline Body Weight & $47.46 \pm 8$ & $48.2 \pm 7.71$ & $0.044^{*}$ \\
\hline BMI $\left(\mathrm{Kg} / \mathrm{m}^{2}\right)$ & $17.38 \pm 2.53$ & $17.66 \pm 2.39$ & $0.039^{*}$ \\
\hline MMP-9 $(\mathrm{pg} / \mathrm{ml})$ & $4356.26 \pm 860.45$ & $4448.84 \pm 1044.75$ & 0.706 \\
\hline Iron $(\mu \mathrm{g} / \mathrm{dl})$ & $71.75 \pm 21.07$ & $120.52 \pm 41.95$ & $0.002^{*}$ \\
\hline Total protein $(\mathrm{mg} / \mathrm{dl})$ & $7.82 \pm 1.07$ & $9.24 \pm 2$ & $0.011^{*}$ \\
\hline Albumin $(\mathrm{mg} / \mathrm{dl})$ & $3.6 \pm 0.8$ & $3.95 \pm 0.53$ & 0.178 \\
\hline Total Bilirubin $(\mathrm{mg} / \mathrm{dl})$ & $0.60 \pm 0.43$ & $0.42 \pm 0.16$ & 0.172 \\
\hline Direct Bilirubin $(\mathrm{mg} / \mathrm{dl})$ & $0.26 \pm 0.14$ & $0.18 \pm 0.08$ & 0.056 \\
\hline
\end{tabular}

* $P<0.05$; parameters show a statistically significant difference (Paired t-test)

BMI - Body Mass Index, MMP-9 - Matrix Metalloproteinase -9.

\section{MMP-9 and Nutritional status}

Table 4 depicts the correlation of MMP-9 with body weight, BMI, iron, total protein and albumin prior and after two months DOTS treatment, showing the correlation coefficient $R$-value and significance $P$ value. Here, there was no significant difference seen

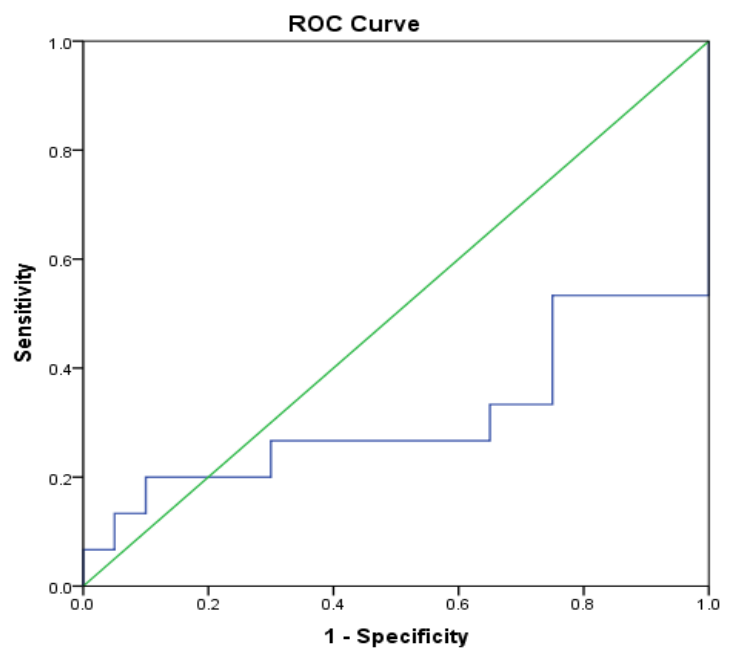

Fig. 1B: ROC Curve depicting MMP-9 levels of controls and patients after two months of DOTS treatment
There was a significant increase in BMI, Iron, total protein $(P<0.05)$ and slight increase in albumin after intensive therapy (Table 3). The MMP-9 levels did not show any significant difference in cases after two months DOTS treatment.

Table 4: Correlation of MMP-9 with body weight, BMI, Serum iron, total protein and albumin between baseline and post DOTS treatment in patients

\begin{tabular}{|c|c|c|c|c|}
\hline \multirow{2}{*}{ Parameters } & \multicolumn{2}{|c|}{ Pre-treatment(n=30) } & \multicolumn{2}{c|}{ Post treatment $(\mathbf{n}=23)$} \\
\cline { 2 - 5 } & $\boldsymbol{R}$-value & $\boldsymbol{P}$-value & $\boldsymbol{R}$-value & $\boldsymbol{P}$-value \\
\hline Weight $(\mathrm{kg})$ & -0.426 & 0.114 & -0.588 & $0.021^{*}$ \\
\hline BMI $\left(\mathrm{kg} / \mathrm{m}^{2}\right)$ & -0.278 & 0.316 & -0.623 & $0.013^{*}$ \\
\hline Iron $(\mu \mathrm{g} / \mathrm{ml})$ & 0.278 & 0.199 & 0.031 & 0.912 \\
\hline Total protein $(\mathrm{mg} / \mathrm{dl})$ & -0.123 & 0.575 & -0.594 & $0.020^{*}$ \\
\hline Albumin $(\mathrm{mg} / \mathrm{dl})$ & -0.325 & 0.131 & 0.353 & 0.197 \\
\hline
\end{tabular}

* $P<0.05$; parameters show a statistically significant difference. (Pearson's Correlation test)

BMI - Body Mass Index 


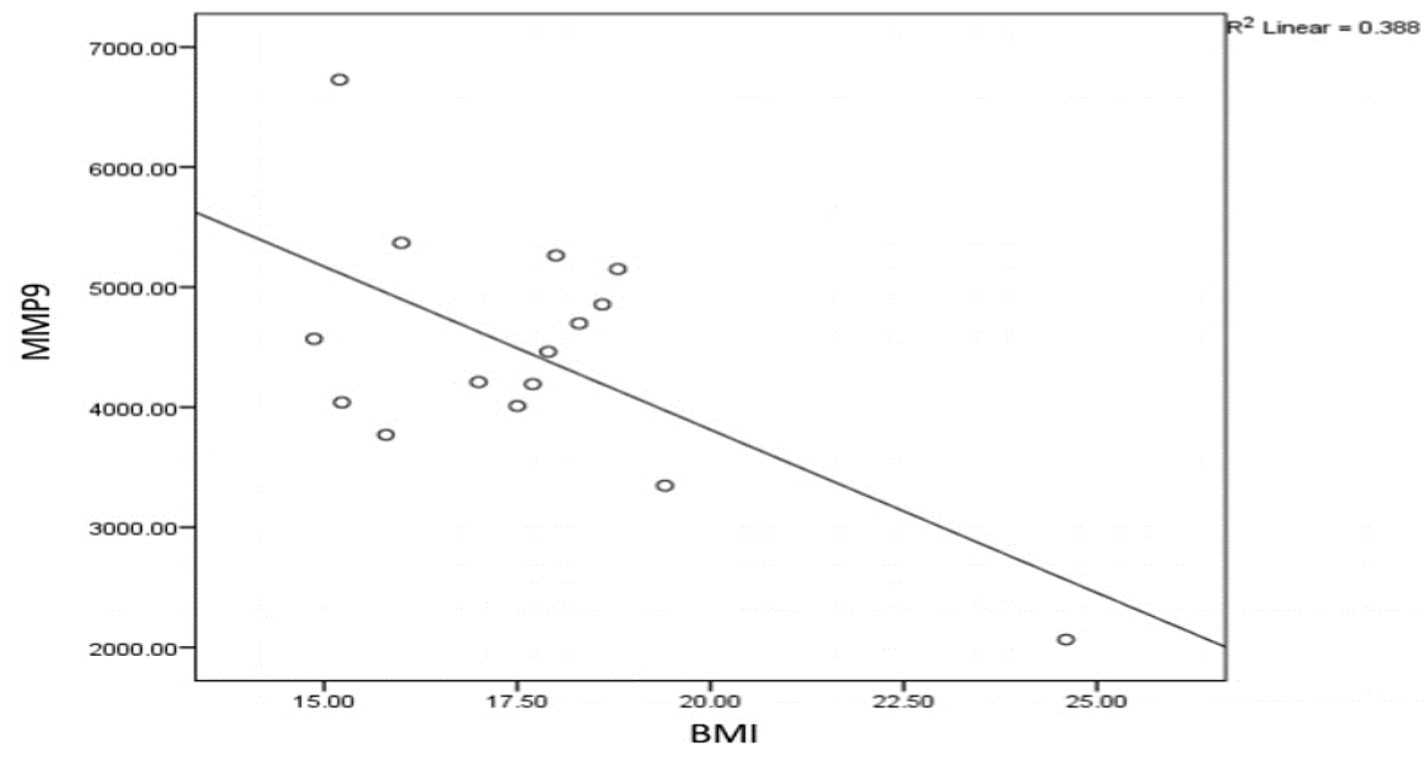

Fig. 2: Correlation of MMP-9 with BMI after two months DOTS treatment

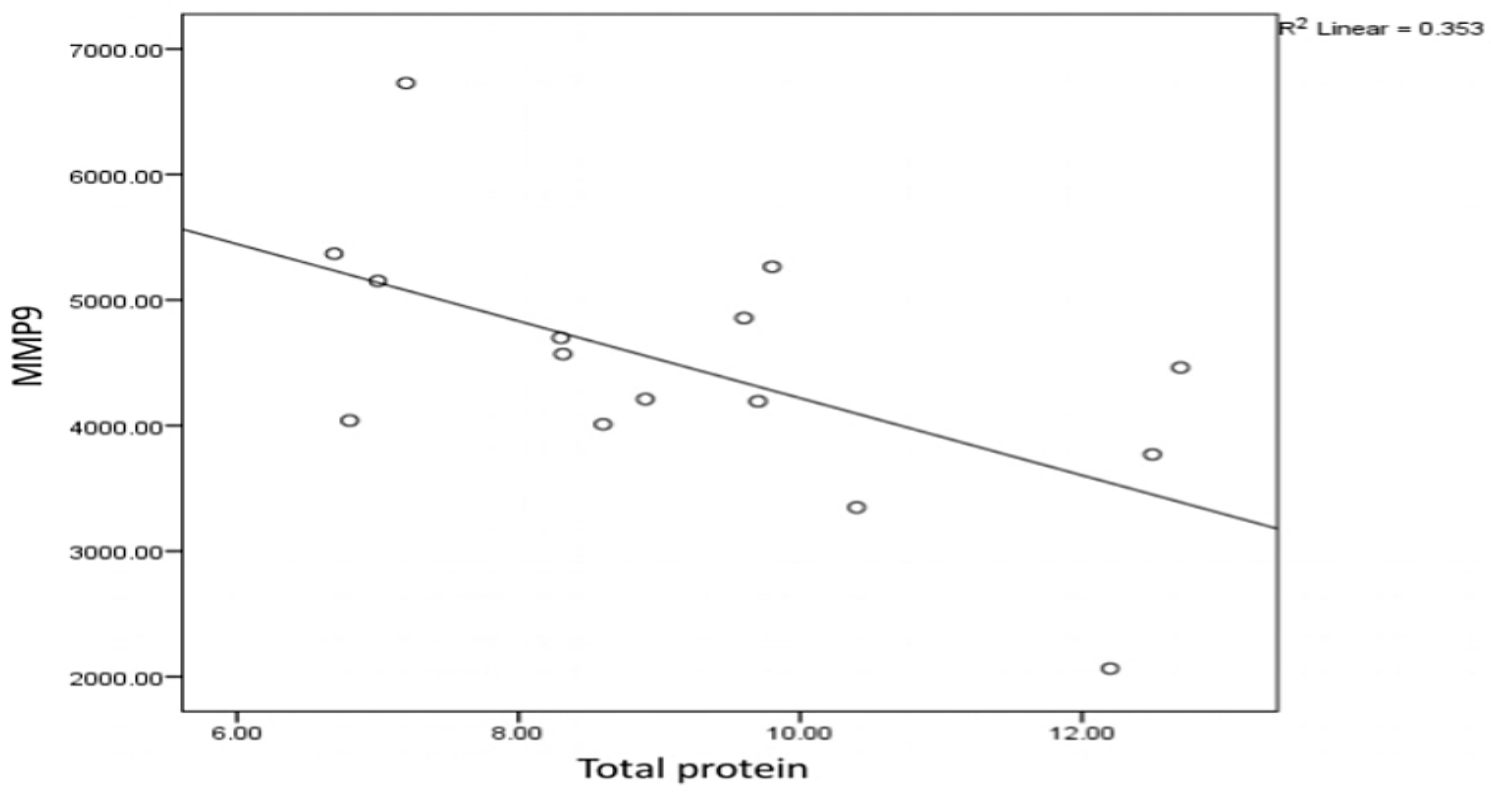

Fig. 3: Correlation of MMP-9 with Total protein after two months DOTS treatment

\section{DISCUSSION}

MMP-9: is a zinc containing type IV collagenase implicated in the breakdown of tissue matrix in normal physiological processes involving tissue turn over and in pathological processes involving extensive tissue breakdown. This function of the enzyme makes it a putative target to understand tissue breakdown in certain disease conditions and also during treatment. In the present study conducted on PTB patients, MMP9 levels did not alter significantly, prior to or post DOTS treatment. Similar report was stated by Majeed $S$ et al(16)in their study on tuberculous meningitis(TBM) patients, where levels of MMP-9 were not affected by anti-tuberculosis drugs which explains the life-long neurological defects even after bacillary clearance in TBM patients On the contrary, certain reports have stated that serum MMP-9 levels were elevated during intensive phase treatment of infiltrative pulmonary tuberculosis(17).Conversely, MMP-9 gene expression in pulmonary epithelial cells infected with mycobacterium tuberculosis was found to be decreased in biopsy specimens obtained from PTB patients(18). Certain studies have reported that there is an in vitro as well as in vivo induction of MMP-9 in mycobacterium infection assigning the role of tissue remodeling to this enzyme (19). Earlier studies also state that upregulation of MMP-9 correlates with presence of granuloma suggesting the role of MMP-9 in inflammatory response in tuberculous pleural disease (20).

In the present study, the ROC curve didn't show any significant difference in MMP-9 of TB patients compared with the MMP-9 of controls, but the sensitivity reduced in the case of post treatment, 
possibly due to the effectiveness of treatment to a certain extent. With a specificity of 75\% MMP-9 cannot be considered to be a specific marker of this disease. Ideally to consider MMP-9 as a good marker for PTB, the AUC should have been above 0.5. whereas in our study AUC for both the test variables showed values $\leq 0.5$ with no significant outcome. Thus MMP-9 fails to be an ideal marker for TB patients prior to or post treatment in our study set up, probably due to the lower number of patients enrolled in this study. Reports also state that although MMP- 9 recruit macrophages to the lung granuloma, it has poor collagenolytic activities (1). Therefore, serum levels of MMP-9 may not be a good indicator of lung tissue cavitation and tissue remodelling that probably takes place during treatment. Probably involvement of other matrix metalloproteinases needs to be explored.

BMI: The results of this study has demonstrated that there was an increase in Body mass index (BMI), Serum iron, and total protein after two months DOTS intensive therapy, from that of baseline values in pulmonary tuberculosis (PTB) patients.

The mean value of BMI in PTB patients before treatment was $17.38 \pm 2.53$ which is considered to be underweight for adults. Nursyam et al., (21) and Mupere et al., (22) in their study have reported that about $41 \%$ and $71.6 \%$ respectively of their subjects had low nutritional status defined by BMI $<18.5$ $\mathrm{Kg} / \mathrm{m}^{2}$. The weight of patients was increased up to 1 $\mathrm{Kg}$ after two months DOTS treatment from that of pretreatment, in turn showing a slight increase in the BMI from that of pre-treatment. Naik et al., (23) have reported that, there was an increase in body weight and BMI after effective treatment. The increase in BMI shows the good response of patients to intensive therapy. About $70 \%$ where malnourished $\left(\mathrm{BMI}<18.5 \mathrm{Kg} / \mathrm{m}^{2}\right)$ in the study done by Nursyam et al., and Mupere et al., $(21,22)$ which may be attributed to decreased appetite and increased catabolism during tuberculosis. It is reported that, persons who are obese and overweight TB patients have a significantly decreased risk of both mortality and disease severity, whereas those who are underweight have an increased risk of mortality (24). However, the changes observed may be due to nutritional supplementation given to the patients during the course of treatment.

Nutritional Status: In adults with pulmonary tuberculosis, serum albumin and serum iron level were found to be strong predictors of survival (8). Here, in our study, there was a significant increase in serum. iron values $(\mathrm{p}=0.002)$, and in Total protein values $(\mathrm{p}=0.01)$, after two months DOTS treatment which shows that the treatment given to the patients has improved their general condition. The antituberculosis treatment would have probably facilitated the absorption of iron in gut by increasing transport protein. Isanaka et al., reported that plasma ferritin level could predict the risk of treatment failure and mortality in pulmonary tuberculosis patients (25). The deficiency of iron or folate, or both also have prevalence to anaemia in TB patients (26). Further the serum total protein levels were increased after the DOTS treatment in TB patients (27) which is in agreement with our report.

There was also a slight increase in serum albumin level although not significant. Santarpia et al., have reported that negative acute phase protein (albumin, prealbumin, and transferrin) decreases in inflammatory disease and increases during recovery phase (28), It is seen that in inflammatory diseases, albumin concentration is reduced by inflammation and malnutrition by decreasing its rate of synthesis (29). Karyadi et al., (30) reported that the concentrations of serum albumin, blood haemoglobin, zinc and retinol in plasma were lower in malnourished TB patients than in well-nourished healthy individuals.

Serum total bilirubin levels decreased post treatment with a significant decrease in direct bilirubin indicating that anti-tuberculosis drugs did not cause liver damage.

MMP-9 and Nutritional status: The study showed a negative correlation of MMP-9 with bodyweight, BMI, and total protein which was statistically significant after two months of DOTS treatment. Body weight, BMI and total protein values increased after two months DOTS treatment. As the BMI lowered, the chances of mortality in TB patients are lowered $(24,30)$. The individuals with lean tissue mass were seen to be most vulnerable to TB rather than individuals with high tissue mass. Mupere et al., (22) in their study reported that, TB patients who already had lean tissue mass showed a poor response to the treatment than the patients with high tissue mass. This may be one of the reasons for the negative correlation of MMP-9 with BMI or bodyweight. At the baseline, MMP-9 did not correlate significantly with any of the parameters. There arises a complex interplay between the different networks of innate and adaptive immunity taking place in MTB infections (31). Nutritional status of an individual plays a key role in boosting the immune status of the affected individuals in this regard. As mentioned in some of previous studies, it is better to boost the protein levels of TB patients, by their supplementation, since proteins are involved in transportation of drugs and building of immune system (10). Lower levels of MMP 9 may contribute to building up of tissue proteins, subsequently increasing the body weight during treatment.

The serum iron levels are mostly concerned with prevalence of anaemia in TB patients. Although serum iron levels significantly increased post treatment, there was no statistically significant correlation of MMP-9 with iron in both baseline and post treatment conditions. Therefore, serum iron appears to be a predictor of improved nutritional status post treatment, 
having a role in tissue remodelling independent of MMP-9.

A smaller number of subjects in this study and a failure in obtaining follow up samples of all the cases enrolled in the study, could be a limitation in instituting our hypothesis.

Based on the results of our study, the improvement in lung damage post DOTS treatment could not be confirmed by blood levels of MMP9, stating that MMP-9 may neither be a useful marker of tissue damage nor a therapeutic target in the management of pulmonary tuberculosis. Nevertheless, serum iron levels proved to be a strong predictor of improvement in nutritional status associated with increase in BMI post DOTS treatment implicating the effectiveness of the therapy. Further, an association between the nutritional status and MMP 9 in PTB patients could not be established.

\section{CONFLICT OF INTEREST}

Authors declare no conflict of interest.

\section{REFERENCES}

1. Elkington, P. T., Ugarte-Gil, C. A., Friedland, J. S. Matrix metalloproteinase in tuberculosis. Eur Respir J 2011;38: 456464.

2. Jennifer, L. T., Jessica, M. H., Steven, A. D., Jolynn, M. T., Linda, S. I., Randall, J. B., et al., Role of Matrix metalloproteinase 9 in Granuloma formation during Pulmonary Mycobacterium tuberculosis infection. Infect. Immun. 2006; 74: 6135-6144.

3. Zarir, F. U. Tuberculosis in India. BMJ. 2015; 23: 1-2.

4. Elkington, P. T., Robert, K. N., Joseph, J. B., Cecilia, M. O., Donna, E. H., Dylan, R. E., et al., Mycobacterium tuberculosis, but not vaccine BCG, specifically upregulates matrix metalloproteinase-1. Am J Respir Crit Care Med. 2005; 172: 1596-1604.

5. Elkington, P. T., Emerson, J. E., Lopez-Pascua, L. D., O'Kane, C. M., Horncastle, D. E, Boyle, J. J., et al., Mycobacterium tuberculosis up-regulates matrix metalloproteinase-1 secretion from human airway epithelial cells via a p38 MAPK switch. J Immunol. 2005; 175: 53335340 .

6. Elkington, P. T., Green, J. A., Emerson, J. E., Lopez-Pascua, L. D., Boyle, J. J., O'Kane, C. M., et al., Synergistic upregulation of epithelial cell matrix metalloproteinase-9 secretion in tuberculosis. Am J Respir Cell Mol Biol. 2007; 37: 431-437.

7. Zhu, X. W., Price, N. M., Gilman, R. H., Recarvarren, S., Friedland, J. S. Multinucleate giant cells release functionally unopposed matrix metalloproteinase-9 in vitro and in vivo. $\mathbf{J}$ Infect Dis. 2007; 196: 1076-1079.

8. Gupta, K. B., Gupta, R., Aterja, A., Verma, M., Vishvkarma, S. Tuberculosis and Nutrition. Lung India. 2009; 26: 9-16.

9. Lee, S. W., Kang, Y. A., Yoon, Y. S., Um, S. W., Lee, S. M., Yoo, C. G., et al., The prevalence and evalution of Anemia associated with tuberculosis. J Korean Med Sci. 2006; 21: 1028-1032.

10. Shindang, J., Bot, Y., Ojo, O., Edeh, O., Essien, C., Bwende, E. Serum albumin/globulin ratio in tuberculosis and HIV patients any relationship? Mycobat Dis. 2016; 6: 199.

11. India TB Report, Revised National TB Control Programme. Annual Status Report. New Delhi: India Offset Press. 2018: p. 24.

12. RayBio Human MMP-9 ELISA Kit Protocol. Norcross, GA: Ray Biotech. 2016; p. 3.
13. Garcic, A. A highly sensitive, simple determination of serum iron using chromazurol B. Clin Chem Acta. 1979; 94: 115.

14. Doumas, B. T., Watson, W. A., Biggs, H. G. Albumin standards and the measurement of serum albumin with bromocresol green. Clin Chem Acta. 971; 31: 87.

15. Gornall, A. G., Bardawill, C. J., David, M. M. Determination of serum proteins by means of the biuret reaction. J Biol Chem. 1949; 177: 751.

16. Majeed, S., Singh, P., Sharma, N., Sharma, S. Role of matrix metalloproteinase-9 in progression of tuberculosis meningitis: a pilot study in patients at different stages of the disease. BMC Infectious diseases. 2016; 16: 722.

17. Esmedlyaeva, D. S., Alexeyeva, N. P., Sapozhnikova, N. V., Dyakova, M. E., Perova, T. L., Kiryukhina, L. D., et al., The system of matrix metalloproteinases and their role in patients with pulmonary tuberculosis.Biomed Khim. 2016; 62: 593598. [Article in Russian]

18. Singh, S., Maniakis-Grivas, G., Singh. U. K., Asher, R. M., Mauri, F., Elkington, P. T., et al., Interleukin-17 Regulates Matrix Metalloproteinase activity in human pulmonary tuberculosis. J Pathol. 2018; 244: 311-322.

19. Quiding-Järbrink, M., Smith, D. A., Bancroft G. J. Production of matrix metalloproteinases in response to mycobacterial infection. Infect Immun. 2001; 69: 5661-5670.

20. Sheen, P., O'Kane, C. M., Chaudhary, K., Tovar, M., Santillan, C., Sosa, J., et al., High MMP-9 activity characterises pleural tuberculosis correlating with granuloma formation. Eur Respir J. 2009; 33: 134-141.

21. Nursyam, E. W., Amin, Z., Rumende, C. M. The effect of vitamin $\mathrm{D}$ as supplementary treatment in patients with moderately advanced pulmonary tuberculous lesion. Acta Med Indones. 2006; 38: 3-5.

22. Mupere, E., Malone, L., Zalwango, S., Okwera, A., Nsereko, M., Tisch, D.J., et al., Tuberculosis Research Unit at Case Western Reserve University. Wasting among Uganda men with pulmonary tuberculosis is associated with linear regain in lean tissue mass during and after treatment in contrast to women with wasting who regain fat tissue mass: Prospective cohort study. BMC Infect Dis. 2014; 14: 24.

23. Naik, A. L., Rajan, M. G., Manjrekar, P. A., Shenoy, M. T., Shreelata, S., Srikantiah, R. M., et al., Effect of DOTS treatment on vitamin $\mathrm{D}$ levels in pulmonary tuberculosis. J Clin Diagn Res. 2017; 11: BC18-BC22.

24. Hanrahan, C. F., Golub, J. E., Mohapi, L., Tshabangu, N., Modisenyane, T., Chaisson, R. E., et al., Body Mass Index and risk of tuberculosis and death. AIDS. 2010; 24: 15011508.

25. Isanaka, S., Mugusi, F., Urassa, W., Willett, W. C., Bosch, R. J., Villamor, E., et al., Iron deficiency and anemia predict mortality in patients with tuberculosis. J Nutr. 2012; 142: 350-357.

26. Roberts, P. D., Hoffbrand, A.V., Mollin, D. L. Iron and folate metabolism in tuberculosis. Br Med J. 1966; 2: 198-202

27. Khan, Z. H., Warke, S. S. Effect of anti-tuberculosis drugs on levels of serum protein in pulmonary tuberculosis patients. IJPRS. 2012; 1: 94-100.

28. Santarpia, L., Grandone, I., Contaldo, F., Pasanisi, F. Butyryl cholinesterase marker as a prognostic marker: a review of the literature. J Cachexia Sarcopenia Muscle 2013; 4: 31-39.

29. Don, B. R., Kaysen, G. Serum Albumin: Relationship to inflammation and nutrition. Seminar in Dialysis. 2004; 6: $432-437$.

30. Karyadi, E., Schultink, W., Nelwan, R. H., Gross, R., Amin, Z., Dolmans, W. M., et al., Poor micronutrient status of active pulmonary tuberculosis patients in Indonesia. J. Nutr. 2000; 130: 2953-2958.

31. de Martino, M., Lodi, L., Galli, L., Chiappini, E. Immune response to mycobacterium tuberculosis: A Narrative Review. Front Pediatr. 2019; 7: 350. 